SOI: $\underline{1.1 / T A S}$ DOI: $10.15863 /$ TAS

\section{International Scientific Journal Theoretical \& Applied Science}

p-ISSN: 2308-4944 (print) $\quad$ e-ISSN: 2409-0085 (online)

Year: 2017 Issue: $01 \quad$ Volume: 45

Published: $30.01 .2017 \quad \underline{\text { http://T-Science.org }}$

SECTION 6. Metallurgy and energy.
E.S. Belyaev

Candidate of technical Sciences, associate professor of «Materials science, technology of materials and heat treatment of metals» Nizhny Novgorod State Technical University n.a. R.E. Alekseev

N. V. Makarov Postgraduate student of the Department «Materials science, technology of materials and heat treatment of metals»

Nizhny Novgorod State Technical University n.a. R.E. Alekseev

Y. A. Getmanovskij

Postgraduate student of the Department «Materials science, technology of materials and heat treatment of metals»

Nizhny Novgorod State Technical University n.a. R.E. Alekseev

\title{
INFLUENCE OF CARBON AND GLASS ON THE HARDNESS METAL- GLASS MATERIALS
}

\begin{abstract}
Installed glass filler and the carbon impact of a particle size less than 50 microns Hardness HRBmetal material on the basis of reduced carbonyl iron powder, BK-1. With the help of mathematical methods of planning it was developed full factorial experiment on the plan 22. The factors that affect the hardness of HRB materials were adopted: carbon content and the concentration of the glass filler. A regression model predictive value of hardness. Analysis showed that the carbon content of glass powder and increase the hardness HRB-metal material. Effect on hardness of HRB carbon-metal material higher than the glass powder. The materials obtained have a heterogeneous microstructure consisting of a matrix metal and fused glass filler particles surrounded by a transition zone from fayalit. Received various metal matrix structure: ferrite; ferrite + pearlite ( 50: 50\%), perlite (100\%). The carbon content in the sintered-metal materials provide the technology.

Key words: powder metallurgy, metal-glass materials, hardness, structure and properties of powder materials.

Language: Russian

Citation: Belyaev ES, Makarov NV, Getmanovskij YA (2017) INFLUENCE OF CARBON AND GLASS ON THE HARDNESS METAL-GLASS MATERIALS. ISJ Theoretical \& Applied Science, 01 (45): 160-166.

Soi: http://s-o-i.org/1.1/TAS-01-45-30 Doi: crostef https://dx.doi.org/10.15863/TAS.2017.01.45.30

\section{ВЛИЯНИЕ СОДЕРЖАНИЯ УГЛЕРОДА И СТЕКЛА НА ТВЕРДОСТЬ МЕТАЛЛОСТЕКЛЯННЫХ МАТЕРИАЛОВ}

Аннотация: Установлено влияния углерода и стеклянного наполнителя с размером частии менее 50 мкм на твердость НRB металлостеклянного материала на основе восстановленного порошка карбонильного железа ВК-1. С помощью методов математического планирования был разработан полный факторный эксперимент по плану 22. В качестве факторов, влияющих на твердость НRВ материалов, были приняты: содержание углерода и концентраџия стеклянного наполнителя. Разработана регрессионная модель прогнозирующая значение твердости. Анализ показал, что содержание углерода и порошка стекла повышают твердость НRB металлостеклянного материала. Влияние углерода на твердость HRB металлостеклянного материала выше, чем порошка стекла. Полученные материаль имеют гетерогенную микроструктуру, состоямую из металлической матрицы и оплавленных частиц стеклянного наполнителя, окруженных переходной зоной из файялита. Получены различные структуры металлической матрицы: феррит; феррит+перлит ( 50:50\%), перлит (100\%). Содержание углерода в металлостеклянных материалах обеспечивалось технологией спекания.

Ключевые слова: порошковая металлургия, металлостеклянные материаль, твердость, структура и свойства порошковых материалов.
\end{abstract}

\section{Введение}

ISPC Perspectives in science for 2017, 
Металлостеклянные материалы - это двухобъемные композиты на основе металлической матрицы и включений стекла. Металлостеклянные материалы получают методом порошковой металлургии формованием исходной шихты и спеканием.

При спекании металлостеклянных материалов протекают различные физикохимические процессы. Наблюдается коагуляция частиц стекла, затекание стекла в поровые каналы под действием капиллярных сил. Затекание стекла в поровые каналы связано с физико-химическим процессом смачивания благодаря протеканию химической реакции ситаллизации по границе раздела включений стекла и железа с образованием ортосиликата железа (II) $\mathrm{Fe}_{2} \mathrm{SiO}_{4}$ - файялита. Ситаллизации стекла способствует наличие окисной пленки на поверхности частиц порошка железа [1-2, 10-11]. Переходная зона файялита между частицами стекла и железа обеспечивает высокую адгезию между разнородными частицами благодаря образованию химических связей.

После спекания металлостеклянные материалы имеют гетерогенную структуру, которая придает высокие антифрикционные свойства и позволяет эффективно использовать их в узлах трения, в том числе в тяжелых условиях: в отсутствии смазки, в вакууме и т.д. Применения таких материалов экономически целесообразно, т.к. их стоимость ниже, чем легированных сталей так же применяемых в узлах трения [1-3].

Механические характеристики (предел прочности на растяжение и твердость) металлостеклянных материалов являются определяющими при проектировании изделий из них. В работе [4] показано, что повышение содержания стекла в металлостеклянных материалах на основе порошка карбонильного железа с незначительным содержанием углерода приводит к снижению предела прочности на растяжение, что может негативно повлиять на эксплуатационные свойства.

Компенсировать разупрочняющее действие включений стекла на композит возможно упрочнением матрицы. Для железа эффективными упрочнителями являются такие химические элементы как углерод, азот, бор и т.д. Наиболее доступным упрочнителем является углерод, который позволяет монотонно повышать прочность и твердость в широком диапазоне концентраций (от 0,1 до 1,0 масс.\%).

Технология порошковой металлургии позволяет получать материалы с заданным составом [1-3, 5, 9], однако введение углерода в железную матрицу является сложной технологической задачей. При введении графита в шихту наблюдается его выгорание при спекании и в вакууме [4], и в водороде [3], что связано с содержанием в порошке железа некоторого количества кислорода и его взаимодействия с защитно-восстановительной средой.

В настоящей работе исследованы структура и свойства материалов на основе восстановленного порошка карбонильного железа с различным содержанием углерода и порошка тарного стекла. Показано влияние содержания углерода в металлической матрице и порошка стекла на твердость HRB металлостеклянного композита.

\section{Материалы, методы исследований и результаты}

Исследование влияния различной структуры матрицы и содержания стекла на твердость материала проводилось с применением методов математического планирования эксперимента. В таблице 1 представлены уровни факторов и интервалы их изменения. Основа шихты - восстановленный порошок карбонильного железа марки ВК-1 ТУ 2436-005-74439740-14. Гранулометрический и химический состав порошка представлен в таблице 2.

Порошок стекла получали размолом стеклобоя в шаровой мельнице в течение 10 часов. От полученного порошка были отсеяны частицы размером менее 50 мкм. Фотографии порошка железа и стекла приведены на рисунке 1. Шихта смешивалась в лабораторном баночном смесителе в течение 240 минут и подвергалась одностороннему прессованию в закрытой прессформе при давлении 600 МПа. Получены прессовки размерами $2,5 \times 4,0 \times 60,0$ мм с пористостью $20 \%$.

Содержание углерода в различных опытах обеспечивает формирование в металлической матрице материала структуры феррита или феррито-карбидной смеси. Содержание стекла принято из расчета его объемного содержания в материале от 7 до 32 об. \% (2,25-13,25 масс.\%). Матрица планирования эксперимента и результаты измерения твердости НRB в каждом опыте приведены в таблице 3 . Различное содержание углерода в проведенных опытах обеспечивалось технологией спекания. Высокое содержание углерода (0,8 \%) получали при спекании в среде генераторного газа (продуктов пиролиза древесного угля), содержание углерода близкое к нулю - в водороде. На основном уровне матрицы планирования спекание проводили вначале в среде генераторного газа, а затем в водороде с применением графитосодержащей засыпки. 


\begin{tabular}{l|lrl|l|ll} 
& ISRA (India) & $=\mathbf{1 . 3 4 4}$ & SIS (USA) & $=\mathbf{0 . 9 1 2}$ & ICV (Poland) & $=\mathbf{6 . 6 3 0}$ \\
Impact Factor: & ISI (Dubai, UAE) $=\mathbf{0 . 8 2 9}$ & PVHIL (Russia) $=\mathbf{0 . 2 3 4}$ & PIF (India) & $=\mathbf{1 . 9 4 0}$ \\
& GIF (Australia) & $\mathbf{0 . 5 6 4}$ & ESJI (KZ) & $=\mathbf{1 . 0 4 2}$ & IBI (India) & $\mathbf{4 . 2 6 0}$
\end{tabular}

\section{Уровни факторов при исследовании металлостеклянных материалов}

Таблица 1

\begin{tabular}{|c|c|c|c|}
\hline \multirow{3}{*}{ Исходные данные } & \multirow{3}{*}{$\begin{array}{c}\text { Кодированное } \\
\text { значение } \\
\text { факторов } x_{i}\end{array}$} & \multicolumn{2}{|c|}{ Натуральные значения факторов } \\
\hline & & Содержание углерода, \% & Содержание стекла, \% \\
\hline & & $x_{1 \text { Нат. }}$ & $x_{2}$ Нат. \\
\hline Основной уровень $x_{i 0}$ & 0 & 0,4 & 7,75 \\
\hline Интервал изменения $\Delta x_{i}$ & - & 0,4 & 5,5 \\
\hline Верхний уровень $x_{i 0}+\Delta x_{i}$ & +1 & 0,8 & 13,25 \\
\hline Нижний уровень $x_{i} 0^{-} \Delta x_{i}$ & -1 & 0,0 & 2,25 \\
\hline
\end{tabular}

Гранулометрический и химический состав порошка ВК-1

Таблица 2

\begin{tabular}{|c|c|c|c|c|c|c|c|}
\hline \multicolumn{2}{|c|}{$\begin{array}{c}\text { Гранулометрический состав, } \\
\text { мкм, не более }\end{array}$} & \multicolumn{5}{|c|}{$\begin{array}{l}\text { Масовая доля химических элементов, } \\
\text { не более }\end{array}$} \\
\hline $\mathrm{X} 10$ & $\mathrm{X} 50$ & $\mathrm{X} 90$ & $F e, \%$ & $C, \%$ & $N, \%$ & $O, \%$ & $S, \%$ \\
\hline 4 & 8 & 18 & основа & $0,02-0,1$ & 0,02 & 0,3 & 0,005 \\
\hline
\end{tabular}

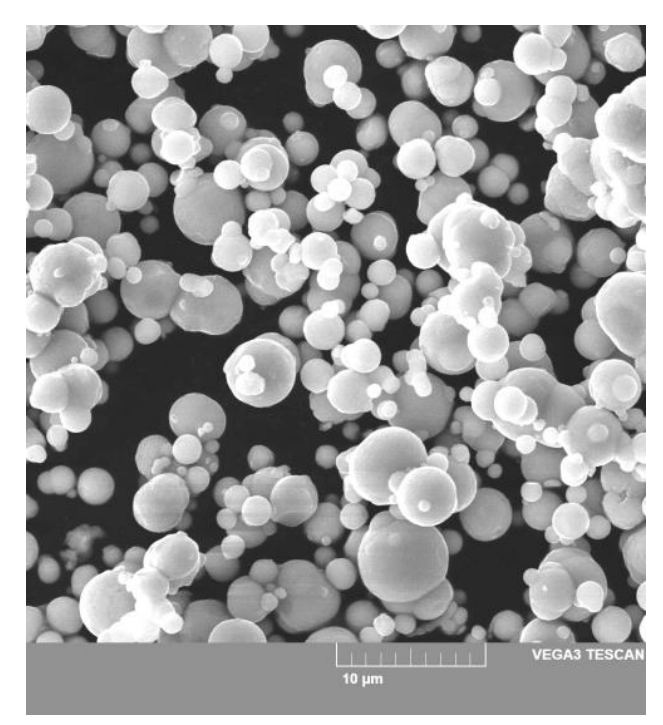

a)

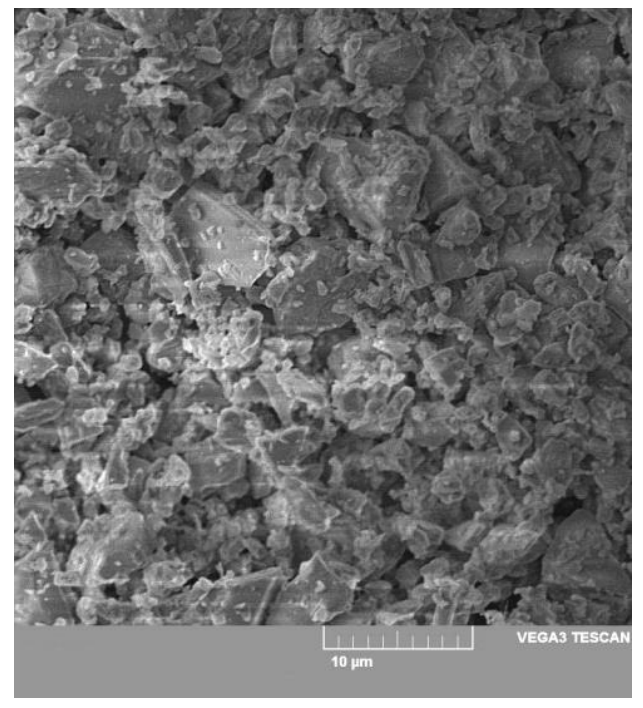

б)

Рисунок 1 - Порошок железа ВК-1 (а) и порошок тарного стекла (б), х5000.

Таблица 3

Матрица планирования эксперимента и результаты измерений.

\begin{tabular}{|c|c|c|c|c|c|}
\hline \multirow{3}{*}{ № опыта $i$} & \multicolumn{4}{|c|}{ Значения факторов } & \multirow{3}{*}{$\begin{array}{c}\text { Параметр оптимизации } \\
y_{l}, \mathrm{HRB} \\
\end{array}$} \\
\hline & \multicolumn{2}{|c|}{$x_{1}$} & \multicolumn{2}{|c|}{$x_{2}$} & \\
\hline & код. & нат. , \% & код. & нат. , \% & \\
\hline \multicolumn{6}{|c|}{ Опыты на верхнем и нижнем уровне } \\
\hline 1 & +1 & 0,8 & +1 & 13,25 & 87 \\
\hline 2 & -1 & 0,0 & +1 & 13,25 & 30 \\
\hline 3 & +1 & 0,8 & -1 & 2,25 & 74 \\
\hline 4 & -1 & 0,0 & -1 & 2,25 & 20 \\
\hline \multicolumn{6}{|c|}{ Параллельные опыты на основном уровне } \\
\hline $5-1$ & 0 & 0,4 & 0 & 7,75 & 50 \\
\hline $6-2$ & 0 & 0,4 & 0 & 7,75 & 54 \\
\hline $7-3$ & 0 & 0,4 & 0 & 7,75 & 53 \\
\hline
\end{tabular}

ISPC Perspectives in science for 2017 , 


\begin{tabular}{|c|c|c|c|c|c|c|}
\hline Impact Factor: & $\begin{array}{l}\text { ISRA (India) } \\
\text { ISI (Dubai, UAB } \\
\text { GIF (Australia) } \\
\text { JIF }\end{array}$ & $\begin{array}{r}=1.344 \\
=0.829 \\
=0.564 \\
=1.500\end{array}$ & $\begin{array}{l}\text { SIS (USA) } \\
\text { PИHЦ (Russia) } \\
\text { ESJI (KZ) } \\
\text { SJIF (Morocco) }\end{array}$ & $\begin{array}{l}=0.912 \\
=0.234 \\
=1.042 \\
=2.031\end{array}$ & $\begin{array}{l}\text { ICV (Poland) } \\
\text { PIF (India) } \\
\text { IBI (India) }\end{array}$ & $\begin{array}{l}=6.630 \\
=1.940 \\
=4.260\end{array}$ \\
\hline
\end{tabular}

Режим спекания во всех опытах $-1100^{\circ} \mathrm{C}$, выдержка 120 минут.

После спекания определяли плотность, расчетное значение пористости прессовок (таблица 4), проводились измерения твердости HRB (общая нагрузка - 980,7 Н (100 кгс); шарик диаметром 1/16') на твердомере ТК-2 «Роквелл». Значение твердости HRB определялось как среднее по 10-ти измерениям в каждом опыте (таблица 3 ).

Исследование микроструктуры выполнено с помощью цифрового микроскопа Keyence VHX-1000 и растрового электронного микроскопа VEGA3 TESCAN.

\section{Плотность и пористость после спекания.}

Таблица 4

\begin{tabular}{|c|c|c|c|c|}
\hline № опыта & 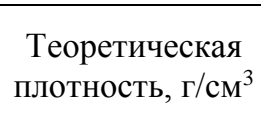 & $\begin{array}{c}\text { Плотность после } \\
\text { прессования и спекания, } \\
\Gamma / \mathrm{cm}^{3}\end{array}$ & $\begin{array}{c}\text { Пористость, } \\
\%\end{array}$ & $\begin{array}{c}\text { Процент от } \\
\text { теоретической } \\
\text { плотности }\end{array}$ \\
\hline 1 & 6,041 & 5,13 & 15,10 & 0,849 \\
\hline 2 & 6,078 & 5,17 & 14,97 & 0,851 \\
\hline 3 & 7,380 & 6,29 & 14,77 & 0,852 \\
\hline 4 & 7,436 & 6,31 & 15,19 & 0,848 \\
\hline $5-7$ & 6,67 & 5,67 & 15,0 & 0,850 \\
\hline
\end{tabular}

Обсуждение результатов исследований

По полученным данным (таблица 3) разработана регрессионная модель изменения твердости HRB в зависимости от содержания углерода и порошка стекла. Регрессионное уравнение имеет вид:

$$
y=52,75+27,75 x_{1}+5,75 x_{2}
$$

где $y$ - расчетное значение твердости HRB;

$x_{1}$ - содержание углерода, в кодовом масштабе;

$x_{2}$ - содержание порошка стекла, в кодовом масштабе.

В полученное уравнение вошли коэффициенты, уровень значимости $p$ которых менее 0,05 . Уровень значимости $p$ рассчитан с помощью критерия Фишера.

Приведем уравнение 1 в натуральный вид. После раскодирования имеем:

$$
H R B=16,5+69,4 X_{1}+1,05 X_{2}
$$

$X_{1}$ - содержание углерода в натуральном масштабе, \%;

$X_{2}$ - содержание стекла в натуральном масштабе, $\%$.

На основании полученной регрессионной модели графически построены проекции изолиний твердости на плоскость (рисунок 2).

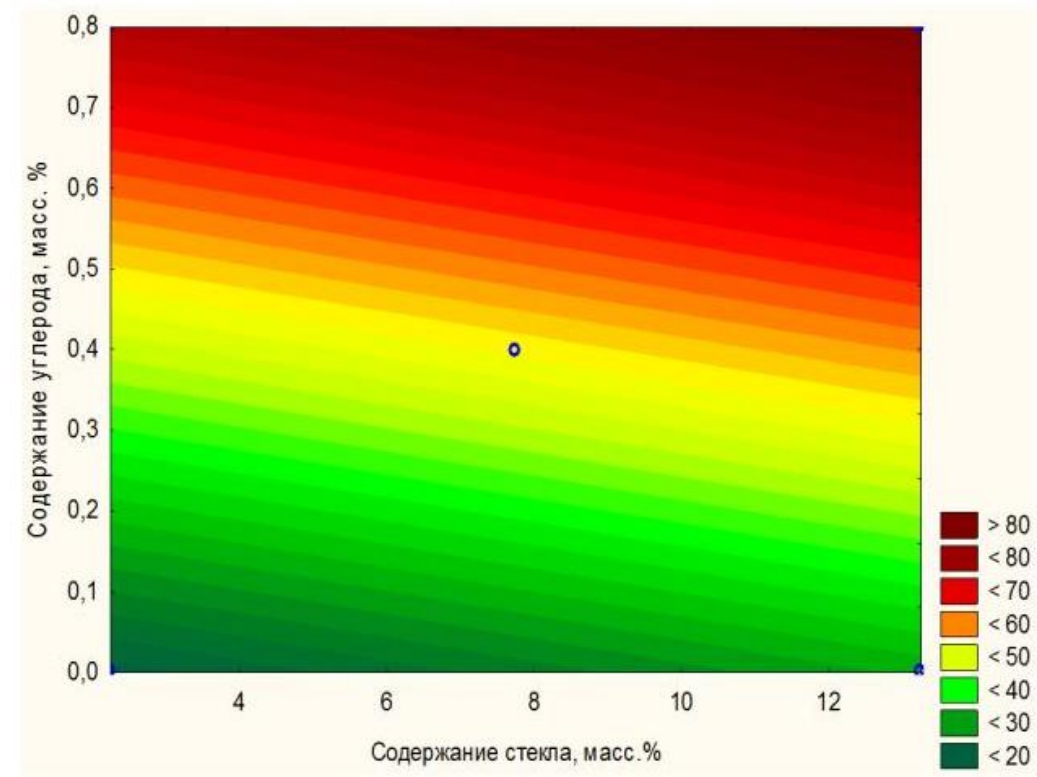

Рисунок 2 - Проекции изолиний твердости на координатную плоскость

ISPC Perspectives in science for 2017, 


\begin{tabular}{l|lr|ll|ll} 
& ISRA (India) & $=\mathbf{1 . 3 4 4}$ & SIS (USA) & $=\mathbf{0 . 9 1 2}$ & ICV (Poland) & $=\mathbf{6 . 6 3 0}$ \\
Impact Factor: & ISI (Dubai, UAE) $=\mathbf{0 . 8 2 9}$ & PUHL (Russia) $=\mathbf{0 . 2 3 4}$ & PIF (India) & $=\mathbf{1 . 9 4 0}$ \\
& GIF (Australia) & $=\mathbf{0 . 5 6 4}$ & ESJI (KZ) & $=\mathbf{1 . 0 4 2}$ & IBI (India) & $\mathbf{= 4 . 2 6 0}$
\end{tabular}

Структура матрицы в полученных материалах имеет различное строение, связанное с содержанием углерода. В результате спекания в различных средах достигнуто различное содержание доли перлита в структуре матрицы, которая соответствует ферритым и перлитным сталям (рисунок 3 ).

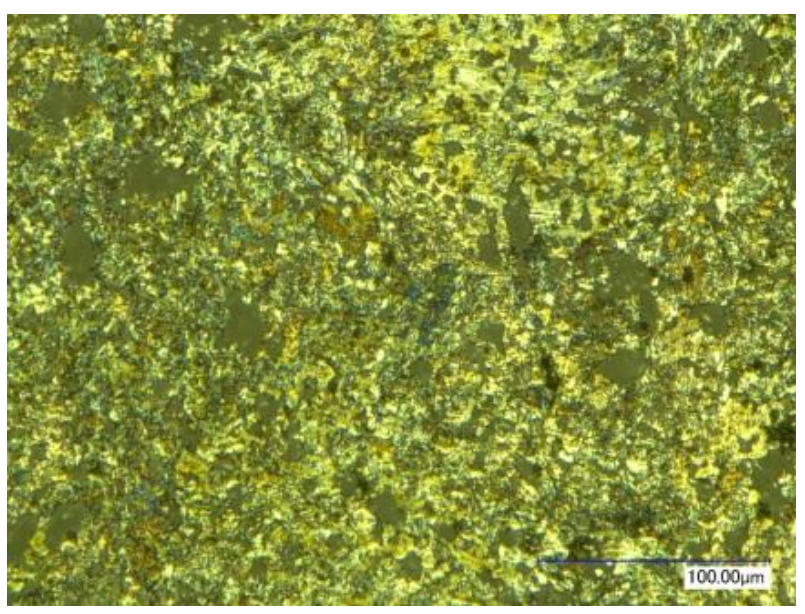

a)

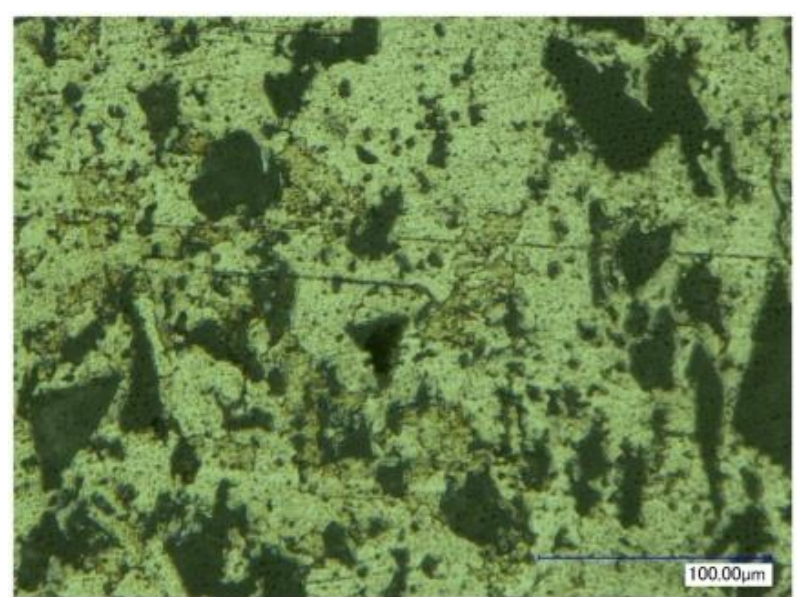

б)

Рисунок 3 - Микроструктура металлостеклянных материалов с различным содержанием углерода $0,8 \%$ (a); 0,0\% (б), после травления, $\mathbf{x 5 0 0 .}$

Содержание углерода и стекла повышают твердость HRB композита, так как коэффициенты уравнения регрессии имеют положительные знаки, при этом вклад содержания углерода в 4,8 раз больше, чем стекла. Парное взаимодействие содержания углерода и порошка стекла оказалось статистически незначимым, значит изменение твердости композита не связано с взаимодействием углерода и стекла.

Содержание углерода монотонно линейно повышает твердость стали до содержания $1 \%$ согласно [6,7] (рисунок 4).

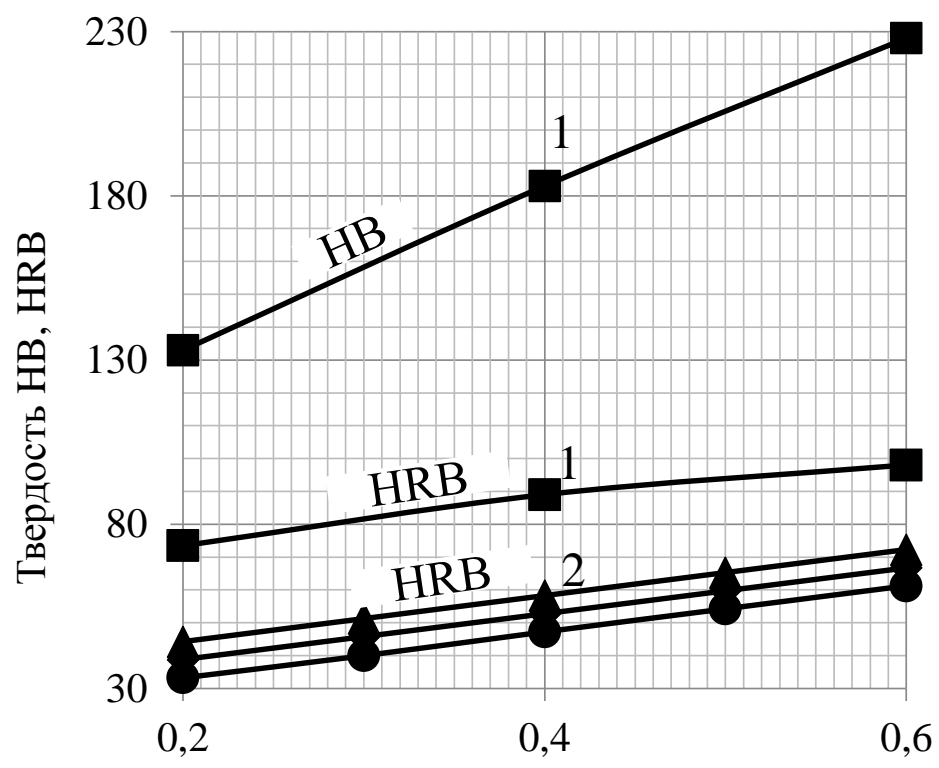

Содержание углерода, \%

1 - компактная сталь (данные твердости НВ, [6,7]; данные НRB получены по таблицам перевода твердости); 2 - металлостеклянные композиции, HRB.

Рисунок 4 - Влияние содержания углерода на твердость.

ISPC Perspectives in science for 2017,

Philadelphia, USA 
Из уравнения 2 видно, что влияние углерода на твердость металлостеклянных материалов значительно превосходит влияние содержания стекла. Динамика роста твердости HRB металлостеклянных материалов (угловой коэффициент, выраженный $b_{0}$ ) с увеличением содержания углерода сопоставима по величине с компактными сплавами железо-углерод [6,7]. Значения угловых коэффициентов линейных зависимостей твердости (рисунок 4), определенных по Бринеллю и Роквеллу, приводятся в таблице 5 .

Таблица 5

Значения угловых коэффициентов функций твердости от содержания углерода для железа с различной пористостью и содержанием порошка стекла

\begin{tabular}{|c|c|c|c|}
\hline № & Вид параметра & Уравнение & $\begin{array}{c}\text { Величина } \\
\text { достоверности } \\
\text { аппроксимации, } \\
\text { R2 }\end{array}$ \\
\hline 1 & НВ (компактной стали) & $y=237,5 x+86,3$ & 0,999 \\
\hline 2 & HRB (компактной стали)* & $y=61,3 x+62,3$ & 0,977 \\
\hline 3 & HRB материала с содержанием стекла 2,25\% & $y=69,4 x+18,86$ & 0,999 \\
\hline 4 & HRB материала с содержанием стекла 7,75 & $y=69,4 x+24,64$ & 1,000 \\
\hline 5 & HRB материала с содержанием стекла 13,25 & $y=69,4 x+30,4$ & 1,000 \\
\hline
\end{tabular}

Анализ данных (таблица 5, рисунок 4) показывает, что угловой коэффициент уравнения твердости HRB для компактных сталей несколько ниже, чем для полученных металлостеклянных материалов. Вероятно, это связано с потерей линейности переводных значений твердости HRB для компактных сплавов, о чем свидетельствуют соответствующие значения величины достоверности аппроксимации. Очевидно, что постоянное содержание порошка стекла не оказывает существенного влияния на процесс упрочнения углеродом железной матрицы, кинетика которого соответствует общепринятым закономерностям для компактных сталей. Увеличение твердости HRB на $1 \%$ содержания углерода составляет 70 единиц, согласно уравнению 2.

Повышение содержания порошка стекла также приводит к монотонному линейному повышению твердости HRB металлостеклянных материалов. Каждый процент содержание стекла увеличивает твердость HRB металлостеклянного материала на 1,05 единицы в рассматриваемом интервале варьирования (таблица 1).

Следует отметить достаточно высокое значение максимальной твердости, полученное в опыте 1 (таблица 3), равное 87 HRВ при пористости $\Pi=15,1 \%$, после спекания. Сопоставимые значения твердости ( 90-91 HRB) получены в работе [8] при использовании железного порошка ПЖВ3-4-160 в композиции железо-графит-медь после спекания и допрессовки $\quad(\Pi=16 \%) . \quad$ Следовательно, применение высокодисперсного порошка железа ВК-1 и добавок порошка стекла сопоставимо с упрочняющим влиянием меди (2-4\%) в шихте без дополнительного уплотнения прессовок после спекания.

\section{Выводы}

1. С помощью регрессионного анализа установлено количественное влияние содержания углерода (доли перлита в структуре железной матрицы) и порошка стекла на твердость HRB металлостеклянных материалов.

2. Увеличение содержания доли перлита в структуре железной матрицы и порошка стекла повышают твердость металлостеклянных материалов на основе железа. Увеличение твердости в основном зависит от доли перлита в структуре железной матрицы (содержания углерода) и в значительно меньшей мере от содержания порошка стекла.

3. Упрочняющее действие углерода в металлостеклянных материалах на основе железа не зависит от содержания стекла, что подтверждается отсутствием статистической значимости парного взаимодействия факторов в уравнении 1. Динамика увеличения твердости с ростом содержания углерода металлостеклянных материалов сходная с компактными сталями. 


\begin{tabular}{l|lrl|l|ll} 
& ISRA (India) & $=\mathbf{1 . 3 4 4}$ & SIS (USA) & $=\mathbf{0 . 9 1 2}$ & ICV (Poland) & $=\mathbf{6 . 6 3 0}$ \\
Impact Factor: & ISI (Dubai, UAE) $=\mathbf{0 . 8 2 9}$ & PUHIL (Russia) $=\mathbf{0 . 2 3 4}$ & PIF (India) & $=\mathbf{1 . 9 4 0}$ \\
& GIF (Australia) & $\mathbf{0 . 5 6 4}$ & ESJI (KZ) & $=\mathbf{1 . 0 4 2}$ & IBI (India) & $\mathbf{= 4 . 2 6 0}$ \\
& JIF & $=\mathbf{1 . 5 0 0}$ & SJIF (Morocco) & $=\mathbf{2 . 0 3 1}$ & & \\
\hline
\end{tabular}

4. Применение высокодисперсного порошка железа и последующее науглероживающее спекание металлостеклянных материалов позволяет получить значение твердости после спекания близкое к композициям железоуглерод-медь после спекания и допрессовки.

\section{References:}

1. (1980) Kompozitsionnyie spechennyie antifriktsionnyie materialyi / Fedorchenko I.M., Pugina L.I. - Kiev: Nauk. dumka, 1980. - 404 p.

2. (1985) Poroshkovaya metallurgiya. Materialyi, tehnologiya, svoystva, oblasti primeneniya Spravochnik / I.M. Fedorchenko, I.N. Frantsevich, I.D. Radomyiselskiy i dr.; Otv. red. I.M. Fedorchenko. - Kiev: Nauk. dumka, 1985. $-624 \mathrm{p}$.

3. (2011) Tehnologiya izgotovleniya i oborudovanie po proizvodstvu poroshkovyih i kompozitsionnyih materialov i izdeliy: ucheb. posobie / V.K. Sorokin, L.S. Shmelev - NGTU im. R.E. Alekseeva. Nizhniy Novgorod, 2011. $184 \mathrm{p}$.

4. Belyaev ES (2015) Struktura i svoystva metallosteklyannyih materialov na osnove poroshka karbonilnogo zheleza / Kolosova T.M., Alekseev V.A., Makarov N.V., Getmanovskij Y.A.// Fundamentalnyie issledovaniya. - 2015. - \# 4. - p. 22-27

5. Belyaev ES (2013) Almazosoderzhaschie materialyi dlya otreznogo instrumenta na osnove zheleznogo poroshka/T.M. Kolosova, V.K. Sorokin, S.V. Kostromin // Sovremennyie problemyi nauki i obrazovaniya. - 2013. - , \#. 2. - p. 209-217.
6. Bogoduhov SI (2015) Materialovedenie: uchebnik / S.I. Bogoduhov, E.S. Kozik. Staryiy Oskol: TNT, 2015. - 536 p.

7. Gulyaev AP (1986) Metallovedenie: uchebnik dlya vtuzov / A.P. Gulyaev. - 6-e izd., pererab. i dop. - M: Metallurgiya, 1986. - 541 p.

8. Sorokin VK (2014) Materialovedenie. Materialyi i tehnologii porshnevyih kolets dvigateley. Monografiya / V.K. Sorokin, S.V. Kostromin. - LAP LAMBERT Academic Publishing, 2014/ - 83 p.

9. Radomyiselskiy ID, Scherban NI (1965) Primenenie stekla v poroshkovoy metallurgii // Poroshkovaya metallurgiya . - 1965. - \# 12. - p. $83-91$.

10. Vlasyuk RZ, Radomyiselskiy ID, Scherban NI (1971) O vzaimodeystvii stekla s metallicheskoy fazoy pri spekanii metallosteklyannyih materialov // Poroshkovaya metallurgiya. -1971. - \# 7. - p. 879 - 882.

11. Vlasyuk RZ, Lugovetskaya ES, Radomyiselskiy ID (1971) Metallosteklyannyiy material // Poroshkovaya metallurgiya. -1971. - \# 5. - p. $657-660$. 